\title{
Changing epidemiological and clinical profile of herpes zoster
}

\author{
Nishit Surti ${ }^{1}$, Som J Lakhani2,", Ranjan C. Raval ${ }^{3}$ \\ ${ }^{\mathbf{1}}$ Assistant Professor, ${ }^{2}$ Associate Professor, ${ }^{3}$ Professor \& HOD, Dept. of Dermatology, ${ }^{1}$ Pramukhswami Medical College, \\ Karamsad, Gujarat, ${ }^{2}$ SBKS Medical Institute \& Research Center, Sumandeep Vidyapeeth, Vadodara, Gujarat, ${ }^{3}$ VS Hospital and \\ NHL Medical College, Ahmedabad, Gujarat, India
}

*Corresponding Author:

Email: somlakhani24@gmail.com

\begin{abstract}
Herpes zoster is a viral infection characterised by unilateral grouped vesicular eruption caused by varicella zoster virus. It occurs because of reactivation of the latent virus in the sensory root ganglion. This article aims to study the incidence, clinical profile, precipitating factors, type of dermatomal involvement and clinical variations of herpes zoster along with its association with HIV infection. The study was done at VS Hospital, Ahmedabad and total of 120 patients ( 72 male and 48 females) were included in the study. All patients (of all ages) diagnosed clinically as herpes zoster and confirmed by Tzanck smear were included in the study. Data related to demographic profile, clinical profile and complications of herpes zoster was collected and analysed. All patients were also screened for HIV and other comorbidities. Most patients presented with vesicular lesions and the most common prodrome was burning sensation. Thoracic ganglion was most commonly involved. The most frequent complications were post herpetic neuralgia and dyspigmentation. Nineteen of our patients had multidermatomal involvement. Twenty of 120 patients (16.6\%) of herpes zoster were HIV positive. Twelve of 120 patients were below 12 years of age. The chances of post herpetic neuralgia increased when treatment was initiated late. This study helped analyse the varied clinical presentations and complications of herpes zoster. Herpes zoster serves as an important early marker for HIV infection. Interesting change in trend was noticed in the demography of herpes zoster and its relatively high incidence in the paediatric age group.
\end{abstract}

\section{Introduction}

Rising encumbrance and changing epidemiology of Herpes zoster in the Asia-Pacific region demands a call to act. This is in relation to prevention of Herpes zoster which requires heightened efforts from medical profession and all concerned. ${ }^{1}$ Herpes zoster, also known as "Shingles" is caused by a neurotrophic varicella zoster virus (VZV ) leading to cutaneous vesicular eruption because of reactivation of the virus that has persisted in sensory nerve root, cranial nerve and autonomic ganglia due to earlier chicken-pox infection. ${ }^{2}$ Herpes zoster has a wide variety of clinical presentations and affects all age groups. There are many complications associated with herpes zoster including post herpetic neuralgia which is troublesome in the elderly. ${ }^{3}$ This study was done to find out epidemiological and clinical profile, precipitating factors, type of dermatomal involvement and to know about varied complications of herpes zoster. It was also done to find out the prevalence of HIV infection in patients with herpes zoster and to find out their clinical presentation when dual viral infection coexisted.

\section{Methodology}

The study was carried over a period of 3 years at VS Hospital and NHL medical college, Ahmedabad. All patients having herpes zoster were included in the study. A total of 120 patients ( 72 males and 48 females) were included in the study after taking informed consent from them. Structured CRF (Case record Form) was filled up and all the relevant clinical details were recorded. This includes clinical history, presentation and past history. History of associated co-morbidity, immunecompromised state and past history of chickenpox was asked. Record of past treatment was meticulously analysed. The diagnosis was made clinically and confirmed by Tzanck smear (Fig. 1). HIV and diabetes screening was done in all patients. (Using serum HIV antibody testing by ELISA, FBS, RBS, PPBS and HbA1C). Based on the clinical history of the patients, other relevant investigations were also done. The patients were treated with either oral Acyclovir or oral Valacyclovir. All patients were followed up after 1 week and thereafter every 15 days for 3 months to look for associated complications, if any.

\section{Results}

A total of 120 patients were included in the study which comprised of 72(60\%) males and 48(40\%) females. Most of the patients in our study were between the age group of 41-50 years. Mean age of presentation was 42.94 years. The minimum age of presentation was 4 years while maximum age was 79 years. There were $9(7.5 \%)$ patients below 10 years and $8(6.67 \%)$ above 71 years.7 $(5.83 \%)$ patients in this study were in $11-20,18$ $(15 \%)$ in $21-30,17(14.16 \%)$ in $31-40,24(20 \%)$ in $41-$ $50,21(17.5 \%)$ in 51-60 and $16(13.33 \%)$ in $61-70$ age group. $12(10 \%)$ patients in this study were below 12 years of age and the mean age of these 12 patients was 8 years. Adolescence age group patients (12 to 18 years) were $3(2.33 \%)$ and 1 patient was 19 years old. 
Most of the patients $(67.5 \%)$ presented within 3 days of onset of the rash and the average time of presentation was 3.42 days.

Prodromal symptoms were recorded in 97(90.8\%) cases. The most common prodromal symptom was burning sensation which was present in $45(37.5 \%)$ patients followed by neuralgic pain in $34(28.3 \%)$ patients. Tingling sensation, watering from eyes, itching, headache and fever were among the other prodromal symptoms. 23 patients reported no prodromal symptom prior to the rash (Table 1). Short lasting unilateral Neuralgiform Headache with Conjunctival Injection and Tearing (SUNCT) type headache was present in two patients.

Table 1: Prodromal Symptoms ( $n=120$ patients)

\begin{tabular}{|l|c|}
\hline \multicolumn{1}{|c|}{ Prodromal symptom } & No of patients (\%) \\
\hline Pain & $34(28.3 \%)$ \\
\hline Itching & $4(3.3 \%)$ \\
\hline Burning & $45(37.5 \%)$ \\
\hline Tingling & $7(5.8 \%)$ \\
\hline Watering from eye & $4(3.3 \%)$ \\
\hline Headache & $2(1.6 \%)$ \\
\hline Fever & $1(0.8 \%)$ \\
\hline No prodromal symptom & $23(19.2 \%)$ \\
\hline
\end{tabular}

In our study, 72 patients had involvement of the right side of the body, while 48 cases had involvement of the left side. 99 of 120 patients $4(82.5 \%)$ had single dermatomal, $19(15.8 \%)$ had multiple dermatomal while disseminated involvement of herpes zoster was found in 2 patients. Thoracic dermatome was most commonly involved (49\% patients) followed by lumbar and ophthalmic (20\% and $14.1 \%$ cases respectively). Table 2 shows the frequency of different dermatomal involvement primary site.

Table 2: Primary Dermatomal site involved in Herpes zoster

\begin{tabular}{|l|c|}
\hline Dermatomal site & No. of patients \\
\hline Cervical & $13(10.8 \%)$ \\
\hline Thoracic & $59(49 \%)$ \\
\hline Lumbar & $25(20 \%)$ \\
\hline Sacral & $5(4 \%)$ \\
\hline Ophthalmic & $17(14.1 \%)$ \\
\hline Maxillary & $1(0.8 \%)$ \\
\hline Total & 120 \\
\hline
\end{tabular}

The most common skin lesions at the time of presentation were vesicles $102(85 \%)$ followed by crusted lesions $10(8.3 \%)$.Haemorrhagic lesions were found in 2 patients(1.6\%), both being HIV positive. Table 3 below shows the type of lesions at the time of presentation of herpes zoster in HIV positive and negative cases.

Table 3: Type of skin lesion at presentation

\begin{tabular}{|l|c|c|c|}
\hline \multicolumn{1}{|c|}{ Type of lesion } & Number of cases & HIV positive & HIV negative \\
\hline Vesicle & $102(85 \%)$ & 13 & 89 \\
\hline Bulla & $5(4 \%)$ & 3 & 2 \\
\hline Haemorrhagic bulla & $2(1.6 \%)$ & 2 & 0 \\
\hline Ulcerative & $1(0.8 \%)$ & 1 & 0 \\
\hline Necrotic & 0 & 0 & 0 \\
\hline Crusted & $10(8.3 \%)$ & 1 & 9 \\
\hline Scarring & 0 & 0 & 0 \\
\hline Total & 120 & 20 & 100 \\
\hline
\end{tabular}

Co-morbid diseases were present in 41 patients (34\%); of which 9 had associated cutaneous disorder and 32 had systemic disorders. The most common systemic comorbidity was diabetes which was present in $13(10.8 \%)$ patients followed by hypertension which was present in $12(10 \%)$ patients. Associated tuberculosis was present in 4 patients. Hepatitis B, nephritic syndrome and rheumatoid arthritis was present in one patient each. Cutaneous diseases like mycosis fungoides was present in 1 , Vitiligo in 2, Psoriasis in 3, Pemphigus vulgaris in 1 and Leprosy in 2 patients.

The most common complication was post inflammatory dyspigmentation which was seen in $34(28.33 \%)$ patients. Post herpetic neuralgia was also common which was present in 22 of 120 patients (18.33\%). The other complications were sepsis (4); scarring (3) and corneal opacity(2). Both patients of corneal opacity were HIV positive. The incidence of post herpetic neuralgia (PHN) was mostly found in patients above 50 years of age. Only 3 out of 22 patients having post herpetic neuralgia were less than 50 years of age. Greater percentage of patients treated with Acyclovir (13 of 49) $(26.53 \%)$ developed post herpetic neuralgia as compared to Valacyclovir (9 of 71) (12.67\%). The time of initiation of treatment was found to have effect on development of post herpetic neuralgia. Of 22 patients who developed post herpetic neuralgia (PHN), 4(18.18 $\%$ ) developed PHN when treatment was initiated within the first 3 days, $8(36.36 \%)$ when treatment was initiated between 3-6 days and $10(45.46 \%)$ when treatment was initiated after 6 days.

Of 120 patients of herpes zoster, 20 patients $(16.6 \%)$ were HIV positive. 10 of these patients were male and 10 were female .The average duration of disease was 3.26 
among HIV positive and 3.81 days among HIV negative. Multiple dermatomal involvement was seen 6 out 20 (30\%) patients in the HIV positive group as compared to only 13 of $100(13 \%)$ in HIV negative group. Also both patients with disseminated herpes zoster were HIV positive. Among the HIV positive patients $10(50$ percent) patients had involvement of ophthalmic division of trigeminal nerve as compared to only 7 patients $(7 \%)$ in the in HIV negative group.

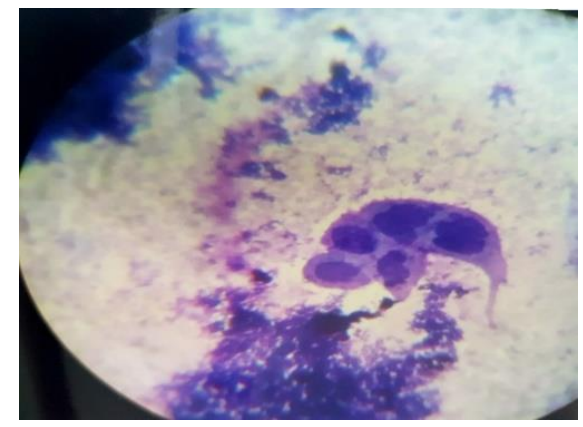

Fig. 1: Tzanck smear shows multinucleated giant cells in herpes zoster

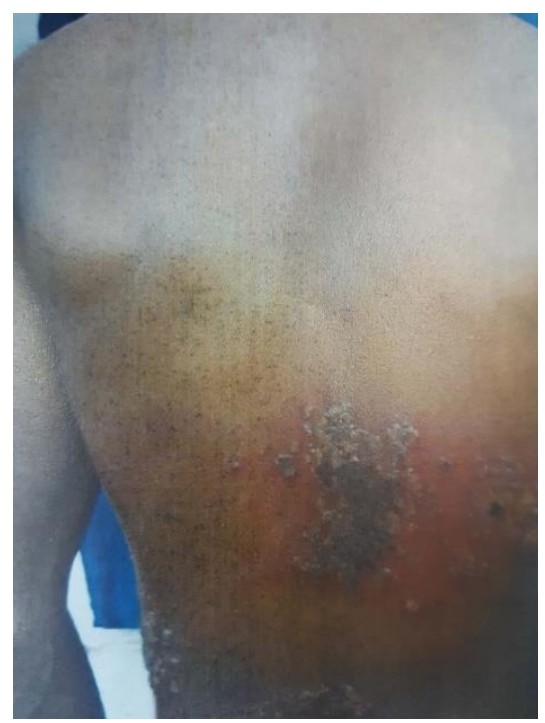

Fig. 2: Shows multidermatomal herpes zoster in a 45 year old male patient with herpes zoster having bilateral involvement

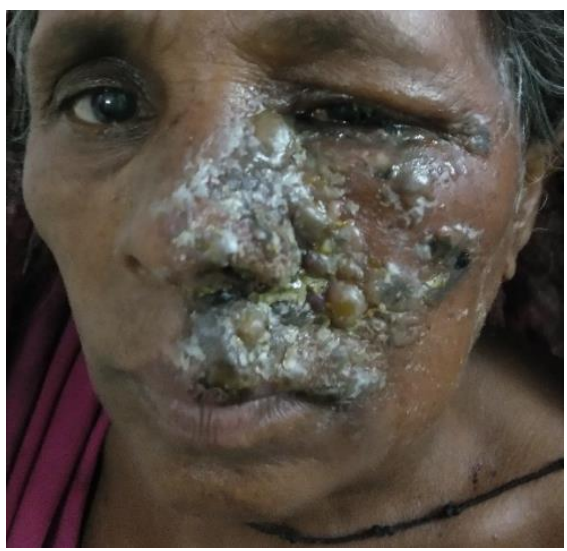

Fig. 3: Above shows herpes zoster ophthalmicus who developed associated corneal opacity

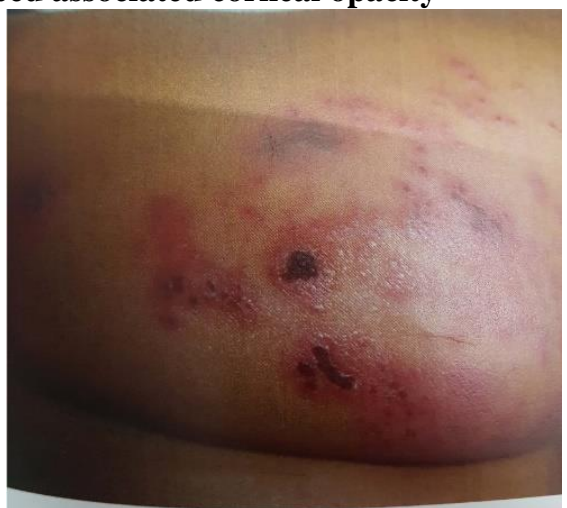

Fig. 4: Involvement of Sacral 2 and 3 ganglions in a HIV positive patient

\section{Discussion}

This study showed that the most common age group affected was between 41 to 50 years. 24 patients of $120(20 \%)$ were in this age group. 21 patients were in 5160,16 in $61-70$ and 8 patients were above 70 years of age, thus 45 out of $120(37.5 \%)$ were above 50 years of age.Most studies have shown increased prevalence with increasing age and is found more commonly after age of 50 years. $^{4}$ In the study done by Dubey et al, the most common age cohort affected was between 14 to 29 years and presentation mean age was 37.65 years. ${ }^{5}$ The mean age of present study population was 42.96 years, The mean age of 164 patients with herpes zoster seen by Goh CL and Khoo L at their dermatology clinic(1994-1995) was 48.8 years. $^{6}$

Time of presentation of our patients was within 3 days in $67.5 \%$ patients while it was $81 \%$ and $45 \%$ in the studies done by Dubey et al as well as by Goh CL, respectively. ${ }^{5,6}$ Early presentations in all these patients could be attributed to the pain and discomfort associated with herpes zoster. The most common prodromal symptom was burning sensation $(37 \%)$ while in the study done by Goh CL and Khoo L, the most common prodromal symptom was pain. ${ }^{6}$ Out of 23 patients who lacked prodromal symptoms, 11 patients were HIV positive. This shows that HIV positive patients may present with 'silent' or painless herpes zoster. ${ }^{7}$ 
In our study, 19(15.8\%) patients had multiple dermatomal involvement (Fig. 2) and 2 had disseminated herpes zoster while in a study done by Talwar et al, multiple dermatomal involvement was found in 35 percent of patients. ${ }^{8}$ Out of 19 patients with multidermatomal involvement of our study, 6 patients(30\%) were found to be HIV positive. Two patients had disseminated Herpes zoster, both were HIV positive. This suggests that patients with multiple dermatomal or disseminated herpes zoster should be screened for HIV infection.

Most common primary site of involvement was thoracic dermatome which was found in $49.2 \%$ cases in our study. Similar observation of common involvement of thoracic dermatome was made by Goh et al and Talwar et al. ${ }^{6,8}$ In present study, $50 \%$ of patients who were HIV positive had involvement of the Ophthalmic division of trigeminal nerve which suggests that HIV positive patients had a predilection to involve this nerve (as shown in Fig. 3). Awareness of varied pattern of these manifestations of herpes zoster among HIV positive patients would help in the early diagnosis and management of HIV infection which could intern decrease the morbidity and improve the quality of life of HIV positive patients. In the general population of Gujarat, the prevalence of HIV infection is $0.38 \% .{ }^{9}$ Our study showed prevalence of HIV in Herpes zoster manifested patients were $16.66 \%$.Furthermore, 12 out of the 20 HIV positive patients(80\%) in our study were below the age of 50 years. Study conducted by DE Sylva $\mathrm{P}$ et al found that majority of patients who were HIV positive was between 21 to 30 years of age..$^{10}$ Evidence like this suggest that healthy persons who develop herpes zoster and are younger than 50 years of age, should be screened for HIV. Apart from vesicular lesions, the other atypical presentations of Herpes zoster were seen in a 6 patients which includes bullous, hemorrhagic, ulcerated and crusted lesions. Herpes zoster is often the first and early manifestation of HIV infection and occurs much before other opportunistic infections start to occur and hence could be an early marker for HIV. ${ }^{11,12}$

In our study, Pediatric patients (excluding adolescent) (up to 12 years) were 12 having mean age of these patients of 8 years. Like adult patients, most common dermatome affected was thoracic $(50 \%)$ in these children also, of which 2 children were HIV positive (Fig. 4). 4 of these children gave past history of herpes zoster while the other patients presented de novo. None of the children had underlying malignancy. The incidence of pediatric herpes zoster is definitely on the rise as seen in our study. Though pediatric herpes zoster can be seen in immunocompetent children, screening such children for immunodeficiency state and malignancy can be recommended. ${ }^{13,14}$ Herpes Zoster infections may occur in association with internal malignancy. ${ }^{15}$

A study done by Wood et al showed that early initiation of treatment reduces the likelihood as well as duration of post herpetic neuralgia (PHN). ${ }^{16}$ Similar observations were made in our study also. Of 22 patients who developed PHN, maximum (10) developed it when treatment was initiated after 6 days while only 4(18.18 $\%)$ developed PHN when treatment was initiated within the first 3 days.

As per recent international classification of Headache, Short-lasting unilateral neuralgiform headaches with conjunctival injection and tearing (SUNCT) is one of the trigeminal autonomic cephalalgias (TACs). ${ }^{17}$ Two of our HIV positive patients had episodic SUNCT headaches which was present in one patient on the anterior aspect of face involving orbital region while in other patient it was in supraorbital face also. It was brief, severe neuralgic pain in bouts which was present for 15 days. They had herpes zoster in trigeminal dermatomal distribution especially ophthalmic division. Akpinar ÇKet al. described two cases of "Herpes Zoster Ophthalmicus" which was presented with SUNCT type headaches as a prodrome and later on developed vesicular desquamation. ${ }^{18}$

\section{Conclusion}

The most common presentation of Herpes zoster infection is acute vesiculobullous eruption with radicular pain in a unilateral dermatomal distribution, most common in thoracic region. Herpes zoster was most commonly seen in the fourth decade of life and pediatric as well as adolescent patients were also affected. Most common prodromal symptom was burning sensation. Prevalence of HIV infection was higher in herpes zoster infected patients as compared to the general population. This suggests that Herpes zoster patients should routinely screened for HIV. Herpes zoster can be first and/or early manifestation of HIV infection in adult as well as pediatric patients.

Funding: No funding sources.

Conflict of interest: None declared.

\section{References}

1. Chen LK, Arai H, Chen LY, et al. Looking back to move forward: a twenty-year audit of herpes zoster in AsiaPacific. BMC Infect Dis. 2017; Page 213.

2. Gilden D., Mahalingam R., Nagel MA, Pugazhenthi S,Cohrs RJ: Review: The neurobiology of varicella zoster virus infection. Neuropathol Appl Neurobiol 2011;441463.

3. Babamahmoodi F, Alikhani A, Ahangarkani F, Delavarian L, Barani H, Babamahmoodi A. Clinical manifestations of herpes zoster, its comorbidities, and its complications in north of Iran from 2007 to 2013. Neurol Res Int 2015

4. Yawn BP, Gilden D. The global epidemiology of herpes zoster. Neurol 2013;Page 928-930.

5. Dubey AK, Jaisankar T J, Thappa DM. Clinical and morphological characteristics of herpes zoster in south India. Indian J Dermatol 2005; Page 203-206.

6. Goh CL, Khoo L., A retrospective study of the clinical presentation and outcome of herpes zoster in a tertiary 
dermatology outpatient referral clinic. Int J Dermatol 1997;Page:667-672.

7. Al-Sardar, Hussain. (2013). A Case of Almost Painless Herpes Zoster Presenting with Symptoms of Cystitis, Penile Numbness, and Acute Vestibular Failure. Case reports in dermatological medicine. 2013. 738579. $10.1155 / 2013 / 738579$.

8. Talwar S, Gupta CM, Dhingra A, Herpes zoster-a clinical profile. Med J Armed Forces India 1991;Page 174-178.

9. Pandey A, Sahu D, Bakkali T, Reddy3, Venkatesh S, Kant S, et al. Estimate of HIV prevalence and number of people living with HIV in India 2008-2009. BMJ Open. 2012;2(5). Published 2012 Oct 1. doi:10.1136/bmjopen2012-000926

10. DE Sylva P, Shah KM, Mani H, Hukkoo AK, Bhattacharya S, Chander Y. HIV infection in herpes zoster. Med J Armed Forces India 1998;Page:182-184.

11. Leppard B, Naburi AE., Herpes zoster: an early manifestation of HIV infection. Afr Health 1998 Nov;Page 5-6.

12. Buchbinder SP, Katz MH, Hessol NA, Liu JY, O'Malley PM, Underwood R, Holmberg SD. Herpes zoster an human immuno-deficiency virus infection. J Infect Dis 1992,Page1153-1156

13. Vora R, Krishna S, Jivani N, A clinicomorphological study of childhood herpes zoster at a rural based tertiary center, Gujarat, India. Indian J Paediatr Dermatol 2016; Page 273-276

14. Prabhu S, Sripathi H, Gupta S, Mukyaprana P, Childhood herpes zoster: A clustering of ten cases. Indian J Dermatol 2009; Page 62-64.

15. Yenikomshian MA, Guignard AP, Haguinet F, LaCasce AS, Skarin AT, TraheyA et al. The epidemiology of herpes zoster and its complications in Medicare cancer patients. BMC Infect Dis 2015,Page 106.

16. Wood MJ, Shukla S, Fiddian AP, Crooks RJ. Treatment of acute herpes zoster: effect of early $(<48 \mathrm{~h})$ versus late $(48-72 \mathrm{~h})$ therapy with acyclovir and valaciclovir on prolonged pain. J Infect Dis 1998;178 Page 81-84.

17. Headache Classification Committee of the International Headache Society. The International Classification of Headache Disorders 3rd edition. Cephalalgia 2018;38:1211.

18. Akpinar ÇK, Doğru H, Erdoğan S, Balci K. Herpes Zoster Ophthalmicus That Mimics the SUNCT Syndrome. Noro Psikiyatr Ars 2016;Page 184-85.

How to cite this article: Surti N., Lakhani S., Raval $\mathrm{R}$. Changing epidemiological and clinical profile of herpes zoster. Indian $J$ Clin Exp Dermatol 2018;4(4):287-91 